Research Article

\title{
Birth preparedness and complication readiness among primigravida women attending tertiary care hospital in a rural area
}

\author{
Monika S. Patil*, Vinod L. Vedpathak, Nandkeshav R. Aswar, Deepali S. Deo, \\ Prashant L. Dahire
}

Department of Community Medicine, Swami Ramananad Teerth Rural Government Medical College, Ambajogai, District Beed, Maharashtra, India

Received: 24 June 2016

Accepted: 12 July 2016

*Correspondence:

Dr. Monika S. Patil,

E-mail: armonadhawle@gmail.com

Copyright: ( ) the author(s), publisher and licensee Medip Academy. This is an open-access article distributed under the terms of the Creative Commons Attribution Non-Commercial License, which permits unrestricted non-commercial use, distribution, and reproduction in any medium, provided the original work is properly cited.

\section{ABSTRACT}

Background: Maternal mortality in developing countries is still alarming. Each pregnancy may face the risk of sudden, unpredictable complications. Birth preparedness and complication readiness (BPACR) is a strategy that encourages pregnant women and their families to effectively plan for deliveries and deal with emergencies. An objective of study was to assess the status of BPACR among primigravida women and factors affecting the status of BPACR.

Methods: A Cross sectional study was conducted among 400 primigravida women attending ANC OPD at tertiary care hospital, from August-November 2015. Data was collected by interviewing the subjects using pre-tested, predesigned structured questionnaire. BPACR index was calculated.

Results: In this study BPACR index was 55.83\%. Most of women (98.14\%) identified skilled birth attendant for delivery. Though acceptable levels of registration of women in first trimester $(79.75 \%)$ and identification of modes of transport in emergency $(72.25 \%)$, TT2 coverage was very low $(77.75 \%)$. About $63 \%$ women were aware about transportation provided by government \& 70.25\% women were aware about importance of 4 or more ANC visits during pregnancy. But only $68.50 \%$ women were aware about consumption of 100 -FSFA tablets, whereas $31.50 \%$ of women had saved money to pay for expenses. Very few $(29.75 \%)$ women identified compatible blood donors. $40.75 \%$ women knew about any one danger signs of pregnancy. Overall no women knew about all 8 danger signs of pregnancy.

Conclusions: Age and education of women and of their husbands plays an important role in awareness regarding components of BPACR.

Keywords: Birth preparedness, Complication readiness, Danger signs, Pregnancy

\section{INTRODUCTION}

Pregnancy in women is a very sensitive period during which unexpected life threatening complications may arise at any stage. Maximum maternal deaths occur during labor, delivery, or within 24 hours of childbirth. Maternal mortality is a huge burden in many developing countries. Globally, more than $40 \%$ of pregnant women may experience acute obstetric problems. The World Health Organization (WHO) estimates that 300 million women in the developing world suffer from short-term or long-term morbidities brought about by pregnancy and childbirth. Most of maternal deaths occur in the developing world. ${ }^{1}$ This is because of several reasons one of which is inadequacy or lack of birth and emergency 
preparedness, which is a key component of globally accepted safe motherhood programs (WHO1994).

The current maternal mortality ratio (MMR) in India is 167 per one lack live births (2011-2013), whereas the country's millennium development goal (MDG) in this respect is 109 per one lack live births by $2015 .^{2,3}$ High levels of infant mortality (50 per 1,000 births), neonatal mortality (29 per 1,000 live births), and maternal mortality (167 per 100,000 live births), and lower levels of deliveries with skilled assistance (45\% - NFHS III) remain major public-health challenges in India. ${ }^{2,4}$

Majority of maternal deaths occur during labor, delivery, and within 24 hours post-partum. Apart from medical causes, there are numerous interrelated socio cultural factors which delay care-seeking and contribute to these deaths. ${ }^{5}$

Thaddeus and Maine documented three delays, (a) Delay in deciding to seek care if complication occurs; (b) Delay in reaching care; and (c) Delay in receiving care. ${ }^{6}$

The Maternal and Neonatal Health (MNH) Program of Johns Hopkins Program for International Education in Gynaecology and Obstetrics (JHPIEGO) developed the birth-preparedness and complication readiness matrix to address these three delays at various levels, including the pregnant woman, her family, her community, health providers, health facilities, and policy-makers during pregnancy, childbirth, and the postpartum period. ${ }^{7}$

At the basic level, the concept of BPACR includes identifying a trained birth attendant for delivery, identifying a health facility for emergency, arranging for transport for delivery and/or obstetric emergency, and saving money for delivery and identification of compatible blood donors in case of emergency. ${ }^{7}$

Complication readiness raises awareness of danger signs among women, families, and communities, thereby improving problem recognition, reduce the delay in deciding to seek care and hasten reaching medical facilities. ${ }^{7}$ A key strategy that can reduce the number of women dying from such complications is making a birth plan that constitutes birth-preparedness and complicationreadiness measures for pregnant women, their spouses and their families.

Since it is not possible to predict which women will experience life-threatening obstetric complications that lead to maternal and neonatal mortality, receiving care from a skilled provider (doctor, nurse, or midwife) during childbirth has been identified as the single most important intervention in safe motherhood. ${ }^{8}$ However, the use of skilled providers in developing countries remains low. According to the National Family Health Survey (NFHSIII), the percentage of deliveries with skilled assistance is only $45 \%{ }^{4}$
Despite the fact that birth preparedness and complication readiness is essential for further improvement of maternal and child health little is known about the current magnitude and influencing factors in India. Additionally, very little work has been done in this rural area, and more so in primigravida women. This study therefore aims to fill the gap by assessing the current status and factors associated with birth preparedness and complication readiness among primigravida women.

\section{METHODS}

Objectives of the study was to assess the status of birth preparedness and complication readiness (BPACR) among primigravida women and to determine the factors affecting the status of BPACR among primigravida women.

Before the start of study, ethical clearance from institutional ethical committee was obtained. We have conducted the hospital based, cross sectional study among primigravida women attending ANC OPD of SRT Rural Government Medical College, Ambajogai, Dist. Beed, from August- December 2015. All Primigravida women who gave consent for study were included in study and who not willing to participate were excluded from the study.

In absence of any reliable information in this area, assuming $50 \%$ of women exhibiting BPACR, with $95 \%$ confidence interval and $10 \%$ allowable error, sample size was calculated by formula, $n=4(\mathrm{pq}) / \mathrm{L}{ }^{2,11,13}$ The final sample size was 400 . We hypothesized $50 \%$ prevalence for BPACR indicators as no prior estimates were available, and an assumed $50 \%$ prevalence provided the largest sample-size. ${ }^{13}$

Before data collection, informed verbal consent was obtained from each participant. A pre formed questionnaire in local language was used for data collection. The study subjects were examined and assisted for ANC check-ups. During examination information was collected regarding identification data, socio-demographic characteristics. Apart from sociodemographic characteristics, status of BPACR, factors affecting BPACR was assessed. BPACR index was measured using a series of questions. BPACR index has been developed by the Johns Hopkins Bloomberg School of Public Health. This index has been used in different studies carried out all over the world including India. BPACR index was calculated by a set of indicators. These indicators are quantifiable and expressed in percentage of women having specific characteristics.

BPACR index was calculated from the following indicators. $^{9-11}$ :

- Percentage of the women who knew about $>8$ danger signs of pregnancy. 
- Percentage of the women who knew about financial assistance provided by government in Janani Suraksh Yojana (JSY).

- Percentage of the women who knew about transportation provided by government in Janani Shishu Suraksh Karyakram (JSSK).

- Percentage of the women who have taken Antenatal Care (ANC) in 1st trimester by skilled provider.

- $\quad$ Percentage of the women who identified skilled birth attendant for delivery.

- Percentage of the women who identified mode of transportation.

- Percentage of the women who saved money to pay for expenses.

- $\quad$ BPACR index was calculated as $\Sigma$ Indicators $/ 7$

Collected data were entered in an excel data sheet. Data was processed by software package Epi Info ${ }^{\text {TM }} 7$ (7.1.2) and the information was analyzed and results were presented in the form of tables. Odds Ratio and Chi square tests $\left(\chi^{2}\right)$ were applied to examine the association between each independent variable and BPACR indicators.

P-value less than 0.05 were considered as statistically significant.

\section{RESULTS}

\section{Sample characteristics}

Total 400 women participated in our study. Mean age of participants is 22.9 years with approximately half (228) of participants were $\leq 22$ years and 114 were $\leq 20$ years old. No one is below $18 \mathrm{yrs}$, and 7 are $\geq 35 \mathrm{yrs}$. $72 \%$ of women were Hindu, one fourth of women were Muslims $(26 \%)$ and rest from other religion. 61\% (244) women from rural area, 39\% (156) were from urban area. Most of women $63 \%$ (251) were unemployed, $29 \%$ (118) were involved in unskilled occupation, and $2 \%$ (7) were involved in each occupation like skilled, semiprofessional and professional and shop owner. However more than half $52 \%$ (208) of participant's husbands were engaged in unskilled occupation. $26 \%$ (103) were belongs to semiskilled and skilled profession, $11 \%$ (45) belongs to clerical and shop owner, 9\% (37) belongs to semiprofessional and professional occupation and only $2 \%$ (7) were unemployed. Approximately half i.e. $45 \%$ (178) of women were educated up to higher secondary class. $35 \%$ (140) up to middle school and $13 \%$ (52) were educated up to graduation and above. Only $7 \%$ (30) women were illiterate. $41 \%$ (163) of participant's husbands were educated up to higher secondary class. $30 \%$ (119) up to middle class and 20\% (81) were educated up to graduation and above. 9\% (37) were illiterate. More than half 59\% (237) of women belongs to joint family and $41 \%$ (163) to nuclear family.

\section{Awareness about ANC care}

Table 1 shows the awareness of study participants about various aspects of ANC care. In this study TT2 immunization coverage was $77.75 \%$ (311). About $70 \%$ (281) of women had 4 or more than 4 ANC visits or planned for the same. Only $68.50 \%$ (274) of women had knowledge about consumption of 100 FSFA tabs, whereas $29.75 \%$ (119) of women had arrangements for blood donors in case of emergency.

Table 1: Awareness about ANC care.

\begin{tabular}{|lll|}
\hline Factors & $\begin{array}{l}\text { No. of women } \\
\text { aware }(\mathbf{N}=\mathbf{4 0 0})\end{array}$ & $\begin{array}{l}\text { Percentage } \\
(\%)\end{array}$ \\
\hline $\begin{array}{l}\text { Registration in first } \\
\text { trimester }\end{array}$ & 319 & 79.75 \\
\hline $\begin{array}{l}\text { TT2 immunization } \\
\text { coverage or planning } \\
\text { for the same }\end{array}$ & 311 & 77.75 \\
\hline $\begin{array}{l}\text { At least 4 or more } \\
\text { ANC visits or } \\
\text { planning for the same }\end{array}$ & 281 & 70.25 \\
\hline $\begin{array}{l}\text { 100 FSFA tablets } \\
\text { consumption }\end{array}$ & 274 & 68.50 \\
\hline $\begin{array}{l}\text { Arrangement for } \\
\text { blood donors in case } \\
\text { of emergency }\end{array}$ & 119 & 29.75 \\
\hline
\end{tabular}

\section{Awareness and practices about BPACR}

Table 2 shows status of birth preparedness. Most of the women $98.25 \%$ (393) were identified skilled birth attendant for delivery, and were planned where to give birth $94.44 \%$ (378). Approximately $80 \%$ (319) of women were registered in first trimester of ANC and were taken ANC care in first trimester by skilled provider. $72 \%$ (289) of women were identified mode of transportation. But only $31.50 \%$ (126) of women were saved money for expenses. Very few, 29.75\% (119) of women were identified compatible blood donors, whereas $63 \%$ of women had knowledge about transportation provided in JSSY. About less than half, 46.25\% (185) of women had knowledge about financial assistance provided in JSY.

Table 3 shows status of awareness about danger signals during pregnancy. Overall, 40.75\% (163) of women knew about any one danger signals of ANC. The most common known danger signal was reduced foetal movement $56 \%$ (222). Other common signals known were pain in abdomen $32 \%$ (126), severe bleeding 30\% (119) and leakage per vagina $30 \%$ (119). Only small percentage of women knew headache $(6 \%)$ and blurring of vision $(2 \%)$ as a danger signals in pregnancy. Overall no one knew about $>8$ danger signals of pregnancy. BPACR index was calculated as $\sum$ Indicator / 7 which were observed to be $55.83 \%$. 
Table 2: Status of birth preparedness.

\begin{tabular}{|lcc|}
\hline Factors & $\begin{array}{l}\text { No. of } \\
\text { women } \\
(\mathbf{N}=400)\end{array}$ & $\begin{array}{l}\text { Percentage } \\
(\%)\end{array}$ \\
\hline $\begin{array}{l}\text { Identified skilled birth attendant } \\
\text { for delivery }\end{array}$ & 393 & 98.14 \\
\hline $\begin{array}{l}\text { Registration of ANC and care } \\
\text { in first trimester by skilled } \\
\text { provided }\end{array}$ & 319 & 79.75 \\
\hline $\begin{array}{l}\text { Identified mode of } \\
\text { transportation }\end{array}$ & 289 & 72.25 \\
\hline $\begin{array}{l}\text { Knowledge about transportation } \\
\text { provided through JSSK }\end{array}$ & 252 & 63.00 \\
\hline $\begin{array}{l}\text { Knowledge about financial } \\
\text { assistance provided through JSY }\end{array}$ & 185 & 46.25 \\
\hline Saved money for expenses. & 126 \\
\hline
\end{tabular}

\section{Relationship between some independent variables and BPACR status}

Table 4 shows factor associated with the independent components of BPACR. Education of women beyond middle school $(\mathrm{P}=0.000)$ and their husbands who were involved in semiprofessional and professional occupation $(\mathrm{P}=0.005)$, were more likely to register in first trimester of pregnancy as compared to illiterates and husbands involved in other occupations respectively.

Again, education of women $(\mathrm{P}=0.000)$ and their husband $(\mathrm{P}=0.000)$ beyond middle school, semiprofessional and professional occupation of their husbands $(\mathrm{P}=0.001)$ and nuclear families $(\mathrm{P}=0.000)$ were more likely to identify the mode of transportation as compared to their counterpart. Whereas, education of women beyond middle school $(\mathrm{P}=0.000)$, husbands who are unemployed and involved in unskilled profession and nuclear families $(\mathrm{P}=0.000)$ were more aware about transportation provided through JSSK when compared to other part.

Table 3: Status of awareness about danger signals during pregnancy.

\begin{tabular}{|lcc|}
\hline Factors & $\begin{array}{l}\text { No. of women } \\
(\mathbf{N}=400)\end{array}$ & $\begin{array}{l}\text { Percentage } \\
(\%)\end{array}$ \\
\hline Awareness of danger signals during pregnancy \\
\hline $\begin{array}{l}\text { Reduced foetal } \\
\text { movement }\end{array}$ & 222 & 56 \\
\hline Pain in abdomen & 126 & 32 \\
\hline Severe bleeding & 119 & 30 \\
\hline Leakage per vagina & 119 & 30 \\
\hline $\begin{array}{l}\text { Swelling of face and } \\
\text { extremities }\end{array}$ & 30 & 7.5 \\
\hline $\begin{array}{l}\text { Palpitation, easy } \\
\text { fatigability and } \\
\text { breathlessness at rest }\end{array}$ & 30 & 7.5 \\
\hline Headache & 22 & \\
\hline Excessive vomiting & 15 & 6 \\
\hline Fever > 24 hrs & 15 & 4 \\
\hline Blurring of vision & 7 & 2 \\
\hline
\end{tabular}

Table 4: Factors associated with the independent components of BPACR.

\begin{tabular}{|c|c|c|c|c|}
\hline \multirow{2}{*}{ Factors $(\mathrm{N}=400)$} & Yes & No & \multirow{2}{*}{$\begin{array}{l}\text { Significance } \\
(\mathrm{P}<\mathbf{0 . 0 5})\end{array}$} & \multirow{2}{*}{$\begin{array}{l}\text { Odds } \\
\text { ratio }\end{array}$} \\
\hline & $\mathrm{n}(\%)$ & $\mathrm{n}(\%)$ & & \\
\hline 1)Registration in first trimester & $318(79.5)$ & $82(20.5)$ & & \\
\hline \multicolumn{5}{|l|}{ Education of women } \\
\hline Illiterate & $15(50.0)$ & $15(50.0)$ & & 1 \\
\hline Up to middle school & $97(69.2)$ & $44(30.8)$ & 0.043 & 2.26 \\
\hline Up to Higher secondary & $155(87.0)$ & $23(13.0)$ & 0.000 & 6.74 \\
\hline Graduation and above & $51(98.1)$ & $1(1.9)$ & 0.000 & 51.0 \\
\hline \multicolumn{5}{|l|}{ Occupation of husband } \\
\hline Unemployed & $6(85.7)$ & $1(14.3)$ & & 1 \\
\hline Unskilled & $156(75.0)$ & $52(25.0)$ & 0.517 & 0.5 \\
\hline Semi-skilled and skilled & $88(85.4)$ & $15(14.6)$ & 0.983 & 0.98 \\
\hline Clerical and shop owner & $32(71.1)$ & $13(28.8)$ & 0.417 & 0.41 \\
\hline Semi-professional and professional & $36(97.3)$ & $1(2.7)$ & 0.177 & 6.0 \\
\hline 2)Awareness of TT2 coverage & $311(77.7)$ & $89(22.3)$ & & \\
\hline \multicolumn{5}{|l|}{ Education of women } \\
\hline Illiterate & $15(50.0)$ & $15(50.0)$ & & 1 \\
\hline Up to middle school & $107(76.4)$ & $33(23.6)$ & 0.003 & 3.24 \\
\hline Up to Higher secondary & $147(82.6)$ & $31(17.4)$ & 0.000 & 4.74 \\
\hline Graduation and above & $42(80.7)$ & $10(19.3)$ & 0.003 & 4.20 \\
\hline \multicolumn{5}{|l|}{ Type of family } \\
\hline Nuclear & $118(72.3)$ & $45(27.7)$ & & 1 \\
\hline
\end{tabular}




\begin{tabular}{|c|c|c|c|c|}
\hline Joint & $193(81.4)$ & $44(18.6)$ & 0.032 & 1.67 \\
\hline \multicolumn{5}{|l|}{ Education of Husband } \\
\hline Illiterate & $22(59.5)$ & $15(40.5)$ & & 1 \\
\hline Up to middle school & $104(87.3)$ & $15(12.7)$ & 0.000 & 4.73 \\
\hline Up to Higher secondary & $119(73.0)$ & $44(27)$ & 0.102 & 1.84 \\
\hline Graduation and above & $66(81.5)$ & $15(18.5)$ & 0.010 & 3.0 \\
\hline 3)Knowledge about transportation provided by JSSK & $252(63.0)$ & $148(37.0)$ & & \\
\hline \multicolumn{5}{|l|}{ Education of women } \\
\hline Illiterate & $15(50.0)$ & $15(50.0)$ & & 1 \\
\hline Up to middle school & $66(47.2)$ & $74(52.8)$ & 0.776 & 0.89 \\
\hline Up to Higher secondary & $134(75.3)$ & $44(24.7)$ & 0.004 & 3.05 \\
\hline Graduation and above & $37(71.2)$ & $15(28.8)$ & 0.027 & 2.47 \\
\hline \multicolumn{5}{|l|}{ Type of family } \\
\hline Nuclear & $119(73.0)$ & $44(27.0)$ & & 1 \\
\hline Joint & $133(56.2)$ & $104(43.8)$ & 0.000 & 0.47 \\
\hline \multicolumn{5}{|l|}{ Occupation of husband } \\
\hline Unemployed & $6(85.71)$ & $1(14.3)$ & & 1 \\
\hline Unskilled & $157(75.5)$ & $51(24.5)$ & 0.534 & 0.51 \\
\hline Semi-skilled and skilled & $52(50.5)$ & $51(49.5)$ & 0.070 & 0.17 \\
\hline Clerical and shop owner & $22(48.8)$ & $23(51.2)$ & 0.069 & 0.16 \\
\hline Semi professional and professional & $15(40.5)$ & $22(59.5)$ & 0.028 & 0.11 \\
\hline 4)Identified mode of transportation & $289(72.25)$ & $111(27.75)$ & & \\
\hline \multicolumn{5}{|l|}{ Education of women } \\
\hline Illiterate & $15(50.0)$ & $15(50.0)$ & & 1 \\
\hline Up to middle school & $88(62.8)$ & $52(37.2)$ & 0.191 & 1.69 \\
\hline Up to Higher secondary & $148(83.1)$ & $30(16.9)$ & 0.000 & 4.93 \\
\hline Graduation and above & $38(73.1)$ & $14(26.9)$ & 0.035 & 2.71 \\
\hline \multicolumn{5}{|l|}{ Education of Husband } \\
\hline Illiterate & $22(69.5)$ & $15(40.5)$ & & 1 \\
\hline Up to middle school & $97(81.5)$ & $22(18.5)$ & 0.005 & 3.01 \\
\hline Up to Higher secondary & $96(58.9)$ & $67(41.1)$ & 0.949 & 0.98 \\
\hline Graduation and above & $74(91.3)$ & $7(8.7)$ & 0.000 & 7.21 \\
\hline \multicolumn{5}{|l|}{ Occupation of husband } \\
\hline Unemployed & $6(85.7)$ & $1(14.3)$ & & 1 \\
\hline Unskilled & $164(78.8)$ & $44(21.2)$ & 0.660 & 0.62 \\
\hline Semi-skilled and skilled & 74(71.8) & $29(28.2)$ & 0.425 & 0.43 \\
\hline Clerical and shop owner & $23(51.2)$ & $22(48.8)$ & 0.086 & 0.17 \\
\hline Semi-professional and professional & $22(59.5)$ & $15(40.5)$ & 0.185 & 0.24 \\
\hline \multicolumn{5}{|l|}{ Type of family } \\
\hline Nuclear & $141(86.5)$ & $22(13.5)$ & & 1 \\
\hline Joint & $156(65.8)$ & $81(34.2)$ & 0.000 & 0.3 \\
\hline 5) Awareness of danger signs of pregnancy & $163(40.75)$ & $237(59.25)$ & & \\
\hline \multicolumn{5}{|l|}{ Education of women } \\
\hline Illiterate & $7(23.3)$ & $23(76.7)$ & & 1 \\
\hline Up to middle school & $52(37.1)$ & $88(62.9)$ & 0.149 & 1.95 \\
\hline Up to Higher secondary & $80(44.9)$ & $98(55.1)$ & 0.026 & 2.68 \\
\hline Graduation and above & $24(46.1)$ & $28(53.9)$ & 0.040 & 2.82 \\
\hline \multicolumn{5}{|l|}{ Age of women } \\
\hline$<20$ & $15(20.2)$ & $59(79.8)$ & & 1 \\
\hline $20-24$ & $89(37.5)$ & $148(62.5)$ & 0.005 & 2.37 \\
\hline $25-29$ & $38(73.0)$ & $15(27)$ & 0.000 & 2.05 \\
\hline $30-34$ & $15(50.0)$ & $15(50.0)$ & 0.002 & 3.39 \\
\hline$\geq 35$ & $6(85.7)$ & $1(14.3)$ & 0.000 & 23.6 \\
\hline
\end{tabular}


Likewise education of women beyond middle school $(\mathrm{P}=0.000)$, and of their husbands up to middle school $(\mathrm{P}=0.000)$ and women belongs to joint family $(\mathrm{P}=0.032)$ were more aware about TT2 coverage in pregnancy as compared to their counterpart. Women aged 30 years and above were more aware about danger signals of pregnancy as compared to women below 20 years of age $(\mathrm{P}=0.000)$.

In this study, education of women (middle school and above) was the most consistent factor which was significantly associated with registration in first trimester, awareness about TT2 coverage, knowledge about transportation provided in JSSK and arrangements of transportation during delivery.

\section{DISCUSSION}

Birth Preparedness and Complication Readiness (BPACR) is a strategy to promote the timely use of skilled maternal and neonatal care, especially during childbirth, based on the theory that preparing for childbirth and being ready for complications reduces delays in obtaining this care. BPACR is an approach based on the premise that preparing for birth and being ready for complications, reduces delays in deciding to seek care in two ways. First, birth preparedness motivates people to plan to have a skilled provider at every birth. If women and families successfully follow through with this plan, the woman will reach care before developing any potential complications during childbirth, thus avoiding delays. Second, complication readiness raises awareness of danger signs, thereby improving problem recognition and reducing the delay in deciding to seek care.

The present study revealed a BPACR index score of almost $55.83 \%$. BPACR indicators like identifying skilled provider for delivery, first check-up within first trimester crossed the benchmarks of $80 \%$ among the study subjects. These findings were likely to have favourable outcome. The corresponding figures about BPACR reported by studies conducted by Mukhopadhyay D K et al in Dinajpur district West Bengal (34.5\%), as well as Acharya A S et al in PHC, Palam, Delhi (41\%), were far less. ${ }^{10,14}$ The linkage of referral transport scheme with utilization of antenatal and intra-natal services might be the reason, especially among poor and marginalized women.

Identifying skilled provider and arrangement of a vehicle for emergency transportation are vital steps in BPACR., Majority of the participants in this study identified skilled provider for delivery $(98.14 \%)$ and had made arrangements of vehicle for transportation in emergency $(72.25 \%)$ as well as were aware of transport schemes (63\%). Comparable findings were shown by a study conducted by S.S. Medical College, Rewa in Madhya Pradesh (2008-09), where majority of the women had identified skilled provider for delivery $(71.1 \%)$ and had made arrangement for transport during emergency
(78.7\%). But both figures were far less being 32\% and 29.5\% respectively in the study conducted by Agrawal S et al at Slum in Indore, M. P, where nearly three-fourths of the deliveries took place in the home. ${ }^{13}$ These findings were contributed by a fact that in rural areas dais had been trained for delivery and women minimally expect to have at least dais during delivery and the government scheme which provide transport.

An important aspect of assessing BPACR in the study subjects is measuring prior knowledge of key danger signs during pregnancy. Awareness of the danger signs of obstetric complications is the first step in appropriate and timely referral for essential obstetric care. The awareness of respondents in this study about any one key danger signs of pregnancy was low $(40.75 \%)$ which was similar to findings shown by study conducted by Tanuka Mandal et al in Darjeeling Dist. West Bengal (43.6\%) and a study conducted by Acharya A. S. et al at PHC, Palam, Delhi $(27.8 \%) .{ }^{10,11}$ This could be because of inadequate information given during ANC visits by healthcare workers. Improving awareness regarding danger signals can improve BPACR index. This means that ANC mothers can be targeted for Information, Education and Communication (IEC) activities for further improvement.

Identification of a blood donor for obstetric emergency was not perceived as an important issue in the present study $(29.75 \%)$. And the issue is similar to most of studies. The corresponding figures from different studies like S. S. Medical College, Rewa. M.P (2.7\%), Mukhopadhyay DK et al at Dinajpur, WB (9.6\%), Mandal T et al at Darjeeling, WB (16.4\%) were far less. Low levels of awareness about arrangement of blood donors in case of emergency will suggest importance of counselling sessions during ANC check-ups.

As evident from earlier research, pregnant women receiving their first check-up within first trimester of ANC and four or more antenatal check-ups during pregnancy were more likely to have favourable outcome. ${ }^{18,19}$ In the present study, BPACR indicators like registration with first check-up within first trimester $(79.75 \%)$ and at least four antenatal check-ups (70.25\%) were showed higher results. Though there was an acceptable level of antenatal visits $(61.3 \%)$ in a study conducted by Mukhopadhyay DK et al at Dinajpur, WB, only half of the women were registered in first trimester of ANC $(50.4 \%) .{ }^{14}$ Findings of study conducted by S. S. Medical College, Rewa in Madhya Pradesh, showed poor utilization of ANC care like low first trimester registration $(31.9 \%)$ and less attendance about four or more ANC visits $(4.8 \%)$. The linkage of monetary incentives like JSY might be the reason for these findings in present study.

Findings of different study showed that, the level of BPACR was low in many societies. Antenatal care provides a golden opportunity to all the pregnant women to provide information, education and communication so 
that they along with their families can make the correct choices especially in event of any complications arising during delivery, childbirth or post-partum. Limitation of study; this was a hospital based study \& there is a need to carry out larger community based study.

\section{CONCLUSION}

The BPACR index in the present study was $55.83 \%$ and there is lot of scope for improvement. BPACR above $50 \%$ may be related to higher levels of identification of trained birth attendant. Although the values affected by lower levels of respondents who saved money and lower awareness of danger signs during pregnancy. In this study TT2 coverage was low and arrangement of blood donors was also very low. Education of women beyond middle school was the most important factor associated with awareness regarding various components of BPACR. Opportunity should be taken to provide information, education and communication to all the pregnant women, during ANC checkups, so that they along with their families can make the correct choices especially in event of any complications arising during delivery, childbirth or post-partum. This opportunity is missed many a times due to a number of reasons which should be addressed at the individual, family, community and the health provider's level. One more positive approach may be access to loans through the community health funds of rural area-based groups. It is important to identify and stimulate rural individuals with a social responsibility to form community groups. Community groups once formed should be encouraged to discuss and determine the need for such a community health fund before encouraging them to begin generating and managing collective savings. All these will be positive steps toward achieving the millennium development goal 5 of safe motherhood and reduction in maternal mortality.

\section{ACKNOWLEDGEMENTS}

The authors are thankful to the Professor and Head of the Department of OBGY for their kind permission and staff in the ANC OPD of Department of OBGY for their help and support during study.

\section{Funding: No funding sources}

Conflict of interest: None declared

Ethical approval: The study was approved by the Institutional Ethics Committee

\section{REFERENCES}

1. WHO, UNICEF and UNFPA. (2007). Maternal Mortality in 2005: Estimates Developed by WHO, UNICEF, UNFPA. Geneva: WHO. Available at: http://www.who.int/whosis/mme_2005.pdf.Accesse d on 2013 Oct 30.

2. Available at: http://www.censusindia.gov.in/vital_statistics/SRS_ Bulletins/Final-MMR Bulletin-2010-12.pdf.
3. United Nations Millennium goals. New York, NY: United Nations; 2004. Available at:http://www.un.org/millenniumgoals accessed on 24 July 2004.

4. International Institute for Population Sciences. National family health survey (NFHS-III), 2005-06: India. V. I. Mumbai: International Institute for Population Sciences. 2007:540.

5. Maternal and Neonatal Health Programme. Monitoring birth preparedness and complication readiness. Tools and indicators for maternal and newborn health Baltimore: JHPIEGO. 2004. Available at: http://www.jhpiego.org/files/ BPACRtoolkit.pdf. Accessed on 2013 Nov 1.

6. Thaddeus S, Maine D. Too far to walk: maternal mortality in context. Soc Sci Med. 1994;38:1091110 .

7. Maternal and Neonatal Health Program. Birth preparedness and complication readiness: a matrix of shared responsibilities. Baltimore, MD: JHPIEGO. 2001:12.

8. Starrs A. The safe motherhood action agenda: priorities for the next decade. Report on the Safe Motherhood Technical Consultation. Colombo, Sri Lanka. New York, NY: Family Care International. 1997:94.

9. Monitoring birth preparedness and complication readiness tools and indicators for maternal and newborn health, published by John Hopkins Bloomberg School of public Health. JHPIEGO. 2004:1-17.

10. Acharya AS, Kaur R, Prasuna JG, Rasheed N. Making pregnancy safer-birth preparedness and complication readiness study among antenatal women attendees of a primary health center, Delhi. Indian Journal of Community Medicine. 2015;40(2).

11. Mandal T, Biswas R, Bhattacharya S, Das D. Birth Preparedness and Complication Readiness Among Recently Delivered Women in a Rural Area of Darjeeling, West Bengal, India. AMSRJ 142015 Volume 2, Number 1

12. NIHFW, UNFPA, SS Medical College, Rewa. A study for assessing birth preparedness and complication readiness intervention in Rewa district of Madhya Pradesh. 2008-9. Available from: http:// nihfw.org/pdf/RAHI-II\%20Reports/REWA.pdf.

13. Agarwal S, Sethi V, Srivastava K, Jha PK, Baqui A. Birth preparedness and complication readiness among slum women in Indore city, India. J Health Popul Nutr. 2010;28:383-91.

14. Mukhopadhyay DK, Mukhopadhyay S, Bhattacharjee S, Nayak S, Biswas AK, Biswas AB. Status of birth preparedness and complication readiness in Uttar Dinajpur District, West Bengal. IJPH.

15. Moran AC, Sangli G, Dineen R, Rawlins B, Yameogo M, Baya B. Birth-preparedness for maternal health: Findings from Koupéla District, Burkina Faso. J Health Popul Nutr. 2006;24:489-97. 
16. Hailu M, Gebremariam A, Alemseged F, Deribe K. Birth preparedness and complication readiness among pregnant women in Southern Ethiopia. PLoS One. 2011;6:e21432.

17. Kaso M, Addisse M. Birth preparedness and complication readiness in Robe Woreda, Arsi Zone, Oromia Region, Central Ethiopia: a cross-sectional study. Reproductive Health. 2014;11:55

18. Government of India. Ministry of Health and Family Welfare. Antenatal care and skilled attendance at birth by ANMs/ LHVs/ SNs. Maternal Health Division, New Delhi, India. 2010.
19. Villar J, Ba'aqeel H, Piaggio G, Lumbiganon P, Belizan J, Farnot U, et al. WHO antenatal care randomized trial for the evaluation of a new model of routine antenatal care. Lancet. 2001;357:1551-64.

Cite this article as: Patil MS, Vedpathak VL, Aswar NR, Deo DS, Dahire PL. Birth preparedness and complication readiness among primigravida women attending tertiary care hospital in a rural area. Int $\mathbf{J}$ Community Med Public Health 2016;3:2297-304. 